\title{
COVID-19 Infection Stigma Scale: psychometric properties
}

Hayam Mohammed Elgohari ${ }^{1}$, Medhat Mohamed Bassiony ${ }^{1}$, Mohammad Gamal Sehlo ${ }^{1 *}$ (D, Usama Mahmoud Youssef ${ }^{1}$, Heba Mohamed Ali ${ }^{2}$, Islam Shahin ${ }^{3}$, Dina Sameh Elrafey ${ }^{4}$ and Rehab Saeed Mahdy ${ }^{1}$

\begin{abstract}
Background: Stigma has been noticed towards patients with COVID-19 in several regions of the world. This social discrimination has contributed to delay in diagnosis and treatment. Also, it may increase the suffering of the patients leading to poor outcome of the illness. Stigma can be assessed with the use of a valid and reliable instrument developed and adapted to our culture. Our objective was to analyze the psychometric properties of COVID-19 Infection Stigma Scale (CISS) for measuring the social stigma among patients with COVID-19 in Egypt. A cross-sectional study that included 182 COVID-19 patients was carried out. The reliability, the convergent validity, and the external and internal consistency of the scale were measured. Factor analysis was used to exclude the weak items.
\end{abstract}

Results: The mean of the COVID-19 Infection Stigma Scale scores was 34.97 \pm 10.35 which was higher than 50\% of the score. Absence of the floor and ceiling effects was observed. Cronbach's alpha coefficient for scale reliability ranged from 0.75 to 0.94 with 0.82 for the total score. The convergent validity coefficients ranged from 0.36 to 0.63 . Test-retest validity Pearson's correlation coefficients ranged from 0.72 to 0.92 with 0.89 for the total score. The split half correlation coefficient was 0.86 , and the reliability coefficient was 0.92 . Both were acceptable correlation coefficients for internal consistency of the scale. Factor analysis showed two factors had latent root greater than 1. The rotated component matrix of the 2 factors revealed that all questions had $r$ value more than 0.30 , which means that no need to exclude any of them.

Conclusion: The results showed that the COVID-19 Infection Stigma Scale is a valid and reliable instrument for the Egyptian people.

Keywords: COVID-19, Stigma scale, Psychometric properties

\section{Background}

A stigma is a standardized disgrace image that is held by a community toward certain people [1]. People stigmatize others who present a threat to effective group function [2]. In case of infectious disease stigmas, the disgrace is being infected with a contagious disease. Infectious diseases threaten a community's ability either by limiting infected persons to perform their roles within a society or by killing them. In addition, infectious diseases by

\footnotetext{
*Correspondence: sehlo68@gmail.com

${ }^{1}$ Department of Psychiatry, Faculty of Medicine, Zagazig University, Zagazig, Egypt

Full list of author information is available at the end of the article
}

spreading from member to member through interaction are extremely affected by the social nature of groups [3].

Stigmatization may increase the consequences of a disease in many ways. First, stigmatization may increase the suffering of patients. Second, patients may delay or avoid seeking medical advice, making the disease control difficult by public health authorities. Third, professionals and volunteers working in the field may also become stigmatized, leading to more stress and burnout [4]. Finally, stigmatization may generate considerable economic losses if people avoid groups or whole regions associated with the disease [5].

\section{Springer Open}

(c) The Author(s). 2021 Open Access This article is licensed under a Creative Commons Attribution 4.0 International License, which permits use, sharing, adaptation, distribution and reproduction in any medium or format, as long as you give appropriate credit to the original author(s) and the source, provide a link to the Creative Commons licence, and indicate if changes were made. The images or other third party material in this article are included in the article's Creative Commons licence, unless indicated otherwise in a credit line to the material. If material is not included in the article's Creative Commons licence and your intended use is not permitted by statutory regulation or exceeds the permitted use, you will need to obtain permission directly from the copyright holder. To view a copy of this licence, visit http://creativecommons.org/licenses/by/4.0/. 
The COVID-19 pandemic is first identified in Wuhan, China, and now spread worldwide. It is transmitted primarily by respiratory droplets and close contact. People became frightened and concerned because of lack of understanding and uncertainty [6,7]. When the outbreak is caused by a new virus, rumors and false information rapidly spread. Stereotypes rapidly appear towards persons who have or may have the illness. In the USA and Europe, for example, Asian people have been treated with suspicion and blamed for COVID-19. Also, some people worry that individuals who have recently completed quarantine have COVID-19 and are contagious, even if there is no current evidence to suggest that case. Blaming the infected people in this manner is hurtful and dangerous, and it may lead to misplaced anger, hostility, or even suicide. It also creates hardships that obstruct the response to the pandemic [8].

To our knowledge, there is no tool to asses COVID-19 stigma worldwide. The aim of this study was to test the validity and reliability of the predesigned scale for measuring stigma associated with the COVID-19 infection.

\section{Methods}

\section{Study design and place of study}

A cross-sectional study was carried out in a governorate in Egypt. In the governorate, COVID-19 patients' management was restricted to isolated governmental hospitals. The patients received the scale either through a paper form or through an electronic Google form sent to them especially in the re-test application.

\section{Population and sample}

The study sample included all positive COVID-19 cases diagnosed by polymerase chain reaction (PCR), which equal to 1399 cases from beginning of the pandemic till 15th June 2020. The sample size was calculated through the Epi-Info (Epidemiological information package) software version 6.1 [9], according to the following collected data: Total number of COVID-19 cases in the governorate was 1399. The frequency of social stigma among infectious diseases in a previous study was found to be $16.1 \%$ [10]. So, at a confidence interval of $95 \%$, the estimated sample size was calculated to be 182 cases. The following inclusion criteria were applied to COVID-19 patients of both sexes, older than 18 years and willing to participate. Patients with psychiatric disorders, substance use disorders, delirium, or with respiratory distress were excluded from the study.

\section{Development of the scale}

To develop the COVID-19 Infection Stigma Scale, an extensive literature review was conducted to assess all general scales for stigma [11]. We considered the Stigma Scale for Chronic Illnesses 8-Item [12], the Reece Stigma
Scale [13], and the Arabic Self-Stigma Scale [14]. This is a self-report quantitative tool that specifically measures the stigma related to COVID-19 infection. The Arabic scale was designed and revised by the authors.

It consists of 14 questions related to feelings such as fear, guilt, and sorrow in coping with the disease, and attitude and self-feeling towards the infection and also anxiety and fear of the reaction of others.

The items were graded on a four-point Likert scale (1 to 4): never (1), rarely (2), usually (3), and always (4). The item scores from the questionnaire were summed, and the scores ranged respectively from 14 to 56 with 14 indicating no stigma and 56 indicating the highest level of stigma.

\section{Pilot test}

The pilot test was intended to collect data on the initial psychometric properties of the scale in Arabic version and permitted a simulation of the field study. The pilot test was applied on $10 \%$ of the sample size (18 patients); they were not included in the study population.

\section{Statistical analysis}

The data were collected between April 2020 and July 2020. Double-data entry was used to avoid possible transcription errors. The software adopted was the Statistical Package for the Social Sciences (SPSS), version 25.0 [15]. The presence of the floor and ceiling effects was verified, and forms with typical answers were excluded from the research when present (the answers are concentrated in the lowest or highest scale score) because they negatively affect the responsiveness of the instrument. The reliability of the scale was measured using Cronbach's alpha. The coefficients were estimated, considering results above 0.70 as acceptable [16]. To analyze the construct validity, the convergent validity of the scale was used, with the aim of verifying the correlations among items and total score [17]. The external consistency of the scale was analyzed by test-retest validity, the participants were asked to fill the scale two times with 2 weeks inter$\mathrm{val}$, and correlations between answers in the 1st and 2nd times were calculated [18]. Also, internal consistency of the scale was analyzed using split half reliability coefficient. Acceptable correlation coefficients for all mentioned methods should be more than 0.30 [19]. KaiserMeyer-Olkin measure of sampling adequacy was used to confirm adequacy of sample size (value of more than 0.50 means adequate sample size). Bartlett's test of sphericity was used to confirm statistically significant relationship between items, and $p$ value less than 0.05 is considered to be significant [20]. Factor analysis was applied to exclude any weak items in the scale. The scree plot graph and extraction of the component factor were used to find the factors with latent root greater than the 
correct one. Extraction method by principal component analysis and rotation method by Varimax with Kaiser normalization was used to find saturation of items in each factor. Items with saturation more than 0.30 was considered to be strong item [21]. The $50 \%$ of the total score (28) was consider to be the cutoff value to discriminate between cases who had stigma and cases who had not, where cases who had $>28$ are considered to have stigma.

\section{Results}

One hundred and eighty-two patients who were diagnosed with COVID-19 and confirmed with PCR test at hospitals of the governorate participated in the study. The patients' age ranged between 18 and 66 years, with a mean age of 38.73 (SD 11). Hundred and five (57.7\%) of the patients were females, 26 (14.3\%) were unemployed, and 68 (37.4\%) were health care workers (HCWs). One out of three and one out of four has either a university degree or post-graduate education respectively. The majority of the studied cases were married (70.3\%), and 102 patients (56\%) were from rural areas, as shown in Table 1.

In Table 2, after excluding forms with typical answers (the answers were located in the lowest or highest scale score), the total patients' number became 166. The means, medians, standard deviations, minima, and maxima of the COVID-19 Infection Stigma Scale scores were calculated (34.97, 38, 10.35, 14, and 56 respectively). As observed, the mean scores were higher than $50 \%$. As for the floor and ceiling effects, the absence of these effects in the dimensions was observed, that is, no answers higher than $15 \%$ were found at the top and bottom of the scale, which favors its responsiveness.

The reliability was analyzed and determined using Cronbach's alpha coefficient. The coefficients if excluded the item and the total alpha of the scale dimensions are displayed in Table 3 . When testing the impact of removing each item on the total alpha coefficient of the scale dimensions, changes were observed, ranging from 0.75 (I am afraid that my family will stay away from me because of my infection) to 0.94 (I feel that it is a must to hide the news of my infection from others) and 0.82 for the total score. Cronbach's alpha was considered good because all items had alpha more than 0.70 .

Regarding split half reliability coefficient of the scale, correlation coefficient was 0.86 , and reliability coefficient was 0.92 ; both are considered acceptable correlation coefficients for internal consistency of the scale.

The construct validity was verified using the convergent validity of the scale; Pearson's correlation coefficients were used between the items and the total score of the scale. The convergent validity coefficients are displayed in Table 4. It ranged from 0.36 (having corona
Table 1 Sociodemographic characteristics of the studied group

\begin{tabular}{|c|c|c|c|}
\hline \multicolumn{2}{|l|}{ Variable } & \multicolumn{2}{|c|}{$(n=182)$} \\
\hline \multirow[t]{2}{*}{ Age } & Mean \pm SD & \multicolumn{2}{|c|}{$38.73 \pm 11$} \\
\hline & Range & \multicolumn{2}{|c|}{$18-66$} \\
\hline Variable & & No. & $\%$ \\
\hline \multirow[t]{2}{*}{ Sex } & Female & 105 & 57.7 \\
\hline & Male & 77 & 42.3 \\
\hline \multirow[t]{8}{*}{ Occupation } & Not working or housewife & 26 & 14.3 \\
\hline & Retired & 4 & 2.2 \\
\hline & Student & 15 & 8.2 \\
\hline & Skilled and worker & 20 & 11 \\
\hline & Free business & 9 & 4.9 \\
\hline & Employer & 13 & 7.1 \\
\hline & Specialist & 27 & 14.8 \\
\hline & HCWs & 68 & 37.4 \\
\hline \multirow[t]{5}{*}{ Education } & Read and write & 7 & 3.8 \\
\hline & Middle & 29 & 15.9 \\
\hline & High & 37 & 20.3 \\
\hline & University & 63 & 34.6 \\
\hline & Post-university & 46 & 25.3 \\
\hline \multirow[t]{2}{*}{ Residence } & Rural & 102 & 56 \\
\hline & Urban & 80 & 44 \\
\hline \multirow[t]{4}{*}{ Marital status } & Single & 40 & 22 \\
\hline & Married & 128 & 70.3 \\
\hline & Divorced & 5 & 2.7 \\
\hline & Widow & 9 & 4.9 \\
\hline
\end{tabular}

$S D$ standard deviation

harms the reputation of my family) to 0.63 (I am afraid of being refused and not accepted by my co-workers). All the studied items obtained coefficients $>0.30$ which are acceptable correlation coefficients.

The external consistency of the scale was analyzed by test-retest validity. Pearson's correlation coefficients were used between the items in the 1st and 2nd time of patients' answers. The results are displayed in Table 4. It ranged from 0.72 (having corona harms the reputation of my family) to 0.92 (having corona makes me feel

Table 2 Measures of the scale and floor and ceiling effect of answers in the scales

\begin{tabular}{|c|c|c|c|}
\hline Variable & & \multicolumn{2}{|c|}{$(n=182)$} \\
\hline \multirow[t]{3}{*}{ Total score } & Mean \pm SD & \multicolumn{2}{|c|}{$34.97 \pm 10.53$} \\
\hline & Median & \multicolumn{2}{|l|}{38} \\
\hline & Range & \multicolumn{2}{|c|}{$14-56$} \\
\hline Variable & & No. & $\%$ \\
\hline Floor & Answers in the minimum score & 6 & 3.3 \\
\hline Ceiling & Answers in the maximum score & 3 & 1.7 \\
\hline
\end{tabular}

SD standard deviation 
Table 3 Alpha coefficients if excluding the item and total alpha of the dimensions

1. I feel shy and ashamed of my infection with coronavirus.

2. I am frustrated and disappointed because of my infection with coronavirus.

3. I feel like an unwanted person.

4. I feel rejected by others because of my illness

5. I feel that being infected with coronavirus is a punishment for something I did in the past.

6. Having corona makes me feel inferior and less than others.

7. Having corona harms the reputation of my family.

8. I am afraid of being refused and not accepted by my co-workers.

9. I will be isolated and away from others to avoid being mistreated.

10. I am afraid that I will lose my work because of my infection.

11. I am afraid that my family will stay away from me because of my infection.

12. I am afraid of being avoided by neighbors in the house because of my infection.

13. I was late in seeking treatment for fear that someone would know that I had corona virus infection.

inferior and less than others) and 0.89 for the total score. All the studied items obtained coefficients $>0.30$ which are acceptable correlation coefficients.

Adequate sample size was tested by using KaiserMeyer-Olkin measure of sampling adequacy which was 0.94. Also, Bartlett's test of sphericity was 0.98 , and $p$ value $<0.001$ indicate highly statistical significant relationship between items.
Table 5 and the scree plot graph (Fig. 1) show the result of extraction of the component factor using the components principal on commonality transactions for the variable; we have arrived at two factors that had latent root greater than 1 . The percentages of interpretation of variances from the total variance of each factor were reached, where the 1st factor has the potential root equal to 8.71 and explains $62.21 \%$ of the total variance.

Table 4 Pearson's correlation coefficients of each item of stigma scale with total score and between participant answers in the 1st and 2nd time

\begin{tabular}{|c|c|c|c|c|}
\hline Variable & $r 1$ & $P$ & $r 2$ & $P$ \\
\hline 1. I feel shy and ashamed of my infection with coronavirus & 0.47 & $<0.001^{* *}$ & 0.86 & $<0.001^{* *}$ \\
\hline 2. I am frustrated and disappointed because of my infection in coronavirus. & 0.58 & $<0.001^{* *}$ & 0.89 & $<0.001^{* *}$ \\
\hline 3. I feel like an unwanted person. & 0.40 & $0.004^{* *}$ & 0.80 & $<0.001^{* *}$ \\
\hline 4. I feel rejected by others because of my illness & 0.46 & $<0.001^{*}$ & 0.83 & $<0.001^{* *}$ \\
\hline 5. I feel that being infected with coronavirus is a punishment for something I did in the past. & 0.39 & $0.006^{*}$ & 0.74 & $<0.001^{* *}$ \\
\hline 6. Having corona makes me feel inferior and less than others. & 0.50 & $<0.001^{* *}$ & 0.91 & $<0.001^{* *}$ \\
\hline 7. Having corona harms the reputation of my family & 0.36 & $0.01^{*}$ & 0.72 & $<0.001^{* *}$ \\
\hline 8. I am afraid of being refused and not accepted by my co-workers. & 0.63 & $<0.001^{* *}$ & 0.89 & $<0.001^{* *}$ \\
\hline 9. I will be isolated and away from others to avoid being mistreated & 0.52 & $<0.001^{* *}$ & 0.73 & $<0.001^{* *}$ \\
\hline 10. I am afraid that I will lose my work because of my infection. & 0.47 & $<0.001^{* *}$ & 0.79 & $<0.001^{* *}$ \\
\hline 11. I am afraid that my family will stay away from me because of my infection. & 0.49 & $<0.001^{* *}$ & 0.81 & $<0.001^{* *}$ \\
\hline 12. I am afraid of being avoided by my neighbors in the house because of my infection. & 0.52 & $<0.001^{* *}$ & 0.88 & $<0.001^{* *}$ \\
\hline 13. I was late in seeking treatment for fear that someone would know that I had corona. & 0.48 & $<0.001^{* *}$ & 0.85 & $<0.001^{* *}$ \\
\hline 14. I feel that it is a must to hide the news of my infection from others. & 0.62 & $<0.001^{* *}$ & 0.92 & $<0.001^{* *}$ \\
\hline Total & - & - & 0.89 & $<0.001^{* *}$ \\
\hline
\end{tabular}

$r 1$ Pearson's correlation coefficient of each item of Stigma scale with total score, $r 2$ Pearson's correlation coefficients between participant answers in the 1st and 2nd time

*Significant $(P<0.05)$, **highly significant $(P<0.001)$ 
Table 5 Result of extraction of the component factor and rotated component matrix

\begin{tabular}{llll}
\hline Variable & & \multicolumn{2}{l}{ Component } \\
\cline { 3 - 4 } & & $\mathbf{1}$ & $\mathbf{2}$ \\
\hline Initial eigenvalues & Total & 8.710 & 1.126 \\
& \% of variance & 62.213 & 8.044 \\
Question & Cumulative \% & 62.213 & 70.257 \\
& q1 & 0.399 & $\mathbf{0 . 7 8 5}$ \\
& q2 & 0.537 & $\mathbf{0 . 6 6 1}$ \\
& q3 & $\mathbf{0 . 6 4 5}$ & 0.524 \\
& q4 & $\mathbf{0 . 7 9 6}$ & 0.352 \\
& q5 & 0.445 & $\mathbf{0 . 6 1 0}$ \\
& q6 & $\mathbf{0 . 5 9 2}$ & 0.532 \\
& q7 & $\mathbf{0 . 8 1 6}$ & 0.360 \\
& q8 & 0.313 & $\mathbf{0 . 7 9 1}$ \\
& q9 & $\mathbf{0 . 7 4 9}$ & 0.265 \\
& q10 & 0.241 & $\mathbf{0 . 7 9 1}$ \\
q11 & q12 & 0.454 & $\mathbf{0 . 5 6 8}$ \\
& q13 & $\mathbf{0 . 8 5 5}$ & 0.317 \\
q14 & 0.249 & $\mathbf{0 . 8 2 4}$ \\
& & $\mathbf{0 . 8 0 9}$ & 0.310
\end{tabular}

Extraction method: principal component analysis. Rotation method: Varimax with Kaiser normalization
On the other hand, the 2nd factor has the potential root equal to 1.13 and explains $70.26 \%$ of the total variance.

Table 5 showed the results of rotated component matrix on the 2 factors which revealed that the 1 st factor explains $62.21 \%$ and included question numbers $3,4,6$, $7,9,12$, and 14, while the 2nd factor explains $70.26 \%$ and included questions $1,2,5,8,10,11$, and 13. All questions had $r$ values more than 0.30 which means that there is no need to exclude any of them.

\section{Discussion}

The objective of the study was to test the psychometric properties of the COVID-19 Infection Stigma Scale among an Egyptian sample of COVID-19 patients. It is a novel tool that aimed to assess and measure the COVID-19-related stigma. It will be of great benefit for further research, application in other cultures, and for decreasing the negative consequences of stigma on the patients. The scale is clear and concise and easy to be applied. The four-point Likert scale gave the chance for wide range of responses. It covers the internal aspect of stigmatization which represent the self-feeling (items from 1 to 6) and the external aspect that appears within the treatment of the others for example at work or at neighborhood (items 7 to 14). The scale was considered to be a very good tool for measuring stigma because of the absence of the floor and ceiling effects, very good reliability (Cronbach alpha range $0.75-0.94$ and 0.82 for the total score), strong convergent validity ( $r$ range 0.36-0.63), strong external consistency (test-retest $r$

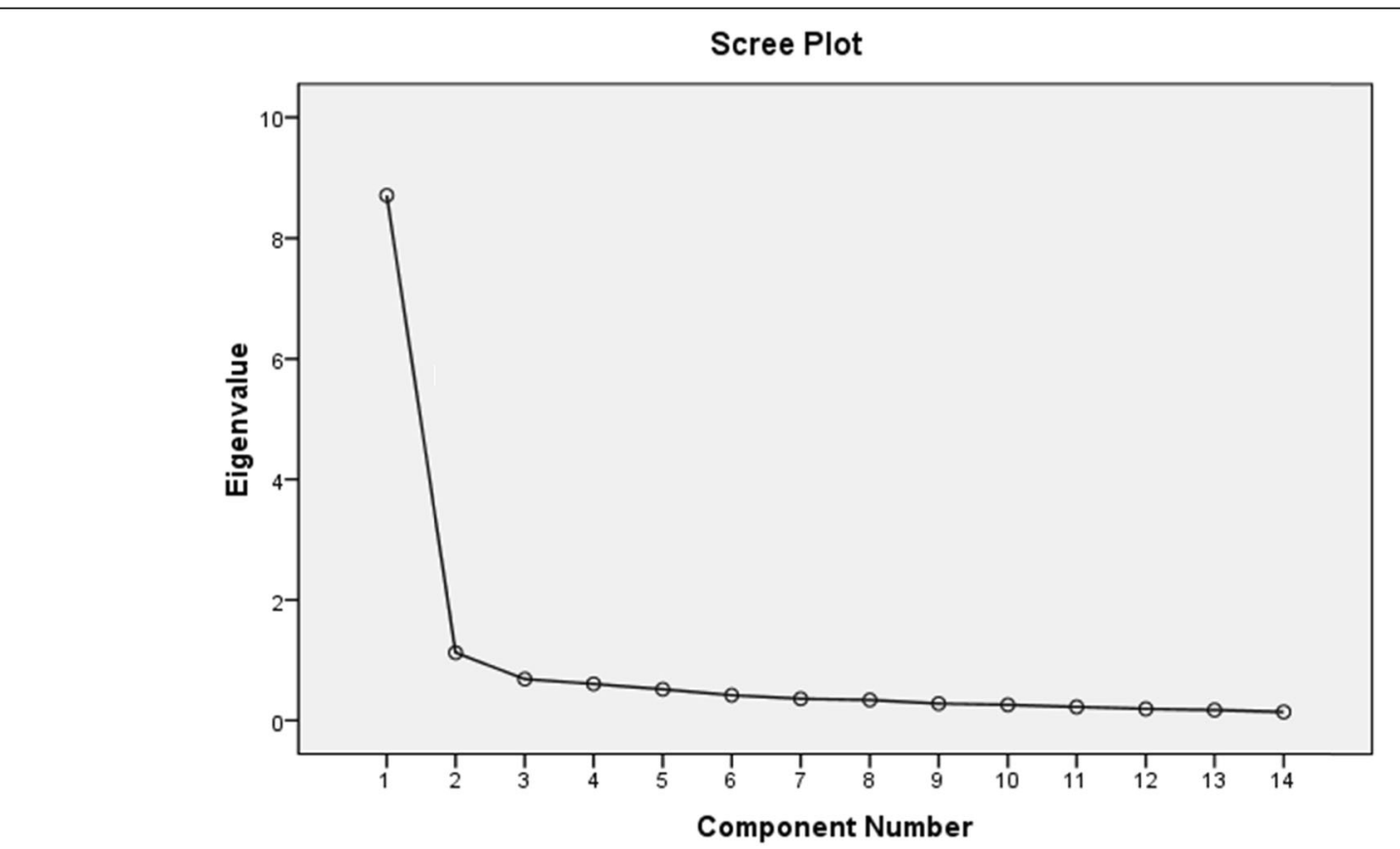

Fig. 1 Scree plot showing the result of extraction of the component factor 
range 0.72 to 0.92 and 0.89 for the total score), and strong internal consistency (split half correlation $r$ was 0.86 and reliability $r$ was 0.92 ). Further verification, such as using confirmatory factor analysis, was a strength for the scale where all questions had $r$ values more than 0.30 which means that there is no need to exclude any of them. The limitation of this study is the selection of the patient sample from one governorate in Egypt. In addition, the questions in the scale did not include reverse-coded questions.

\section{Conclusion}

The scale showed favorable initial psychometric properties in the pilot test, which sustains the validity and reliability of the scale. It is the first scale validated in the Arabic language, which might be helpful for other Arabic-speaking countries that are liable to COVID-19 stigma. The COVID-19 Infection Stigma Scale can stimulate the advancement of operational research and the development of strategies to reduce the stigma related to COVID-19. It could be used in other cultures after translation into other languages. We recommend further studies to assess the risk factors of stigma in our society.

\section{Supplementary Information}

The online version contains supplementary material available at https://doi. org/10.1186/s41983-021-00317-0.

\section{Additional file 1}

\section{Acknowledgements}

The authors would like to thank all participants in the study.

\section{Authors' contributions}

Study conception and design: $\mathrm{HE}, \mathrm{MB}, \mathrm{HA}, \mathrm{MS}, \mathrm{ES}$, and RM. Data collection: $H E, D E$, and HA. Data analysis and interpretation: DE, and HA. Drafting of the article: HE, MS, UY, and RM. Revision of the article: HE, MS, UY, and RM. The authors read and approved the final manuscript.

\section{Funding}

None.

\section{Availability of data and materials}

All data generated or analyzed during this study are included in this published article.

\section{Declarations}

\section{Ethics approval and consent to participate}

After complete written description of the study to the subjects, a written informed consent was obtained from all participants in this study in the form of answering a question at the beginning of the survey that is "Do you agree to participate in this study?" with yes and no answers. The ethical approval was obtained from the research ethics committee of the faculty of medicine, Zagazig University, under number 6258/2020.

\section{Consent for publication}

Not applicable.

\section{Competing interests}

The authors declare that they have no competing interests.

\section{Author details}

'Department of Psychiatry, Faculty of Medicine, Zagazig University, Zagazig, Egypt. ${ }^{2}$ Department of Psychology, Faculty of Arts, Zagazig University, Zagazig, Egypt. ${ }^{3}$ Cairo Mood Center, Cairo, Egypt. ${ }^{4}$ Department of Community, Environmental and occupational Medicine, Faculty of Medicine, Zagazig University, Zagazig, Egypt.

Received: 11 March 2021 Accepted: 7 May 2021

Published online: 17 May 2021

\section{References}

1. Smith R. Language of the lost: an explication of stigma communication. Commun Theory. 2007;17(4):462-85. https://doi.org/10.1111/j.1468-2885.2007.00307.x.

2. Neuberg SL, Smith DM, Asher T. Why people stigmatize: toward a biocultural framework. Soc Psychol Stigma. 2000:31-61 Guilford Press.

3. Smith RA, Hughes D. Infectious disease stigmas, maladaptive in modern society. NIH Public Access Commun Stud. 2014;65(2):132-8.

4. Snyder M, Omoto AM, Crain AL. Stigmatization of AIDS volunteers. Am Behav Sci. 1999;42(7):1193-211. https://doi.org/10.1177/00027649921954831.

5. Nsagha DS, Rosenburg N, Diesel H, Sab CM, Taliaferro D. International collaboration to enhance the fight against HIV/AIDS: report of a consultative meeting between the University of Buea in Cameroon and the Goldfarb School of Nursing in the USA. J Pub Health Africa. 2011;2(2):e22.

6. Tang JW, Tambyah PA, Hui DSC. Emergence of a novel coronavirus causing respiratory illness from Wuhan, China. J Infect. 2020;80(3):350-71. https://doi. org/10.1016/j.jinf.2020.01.014.

7. Arshad S, Baloch M, Ahmed N, Arshad A, labal A. The outbreak of coronavirus disease 2019 (COVID-19). An emerging global health threat. J Infect Public Health. 2020;13(4):644-6. https://doi.org/10.1016/j.jiph.2020.02.033.

8. Dhanani LY, Franz B. Unexpected public health consequences of the COVID-19 pandemic: a national survey examining anti-Asian attitudes in the USA. Int J Public Health. 2020;65(6):747-54. https://doi.org/10.1007/s00038-020-01440-0.

9. Dean AG, Dean JA, Epi Info, version 6. A word-processing, database, and statistics program for public health on IBM-compatible microcomputers. Atlanta: Epidemiology Program Office. Centers for Disease Control and Prevention; 1994.

10. Lee SI, Chan LY, Chau AM, Kwok KP, Kleinman A. The experience of SARSrelated stigma at Amoy Gardens. Soc Sci Med. 2005;61(9):2038-46. https:// doi.org/10.1016/j.socscimed.2005.04.010.

11. McCoach DB, Gable RK, Madura JP. Review of the steps for designing an instrument. In: Instrument development in the affective domain. New York: Springer; 2013. p. 277-84.

12. Molina $Y$, Seung W, Choi CD, Rao D. The Stigma Scale for Chronic Illnesses 8-Item Version (SSCl-8): development, validation and use across neurological conditions. J Behav Med. 2013;20(3):450-60.

13. Shacham E, Rosenburg N, Önen NF, Donovan MF, Overton ET. Persisting HIV-related stigma among an outpatient US clinic population. Int J STD AIDS. 2015;26(4):243-50.

14. Ali HM. Self-stigma and its relationship to self-esteem and insight among schizophrenic. Stud Psychol Educ Guid J, Fac Educ, Assiut Univ. 2020;8(8):1-60.

15. IBM crop. Released. IBM SPSS statistics for windows, Version 25.0. Armonk: IBM crop; 2017.

16. Taber K. The use of Cronbach's alpha when developing and reporting research instruments in science education. Res Sci Educ. 2018;48(6):1273-96. https://doi.org/10.1007/s11165-016-9602-2.

17. Fayers PM, Machin D. Assessment, analysis and interpretation. Quality of life. New York: Wiley; 2007.

18. Woods SP, Scott J, Sires DA, Grant I, Heaton RK, Tröster Al, et al. Action (verb) fluency: Test-retest reliability, normative standards, and construct validity. J Int Neuropsychol Soc. 2005;11(3):408-15. https://doi.org/10.1017/S1355617705050460.

19. Terwee CB, Bot SD, de Boer MR, Windt DA, Knol DL, Dekker J, et al. Quality criteria were proposed for measurement properties of health status questionnaires. J Clin Epidemiol. 2007;60(1):34-42. https://doi.org/10.1016/j.jclinepi.2006.03.012.

20. Scheridan JC and Lyndall GS (2001) Version 10.0 for windows Singapore, SPSS Analysis Without Anguish, John Wiley and Sons (Australia) Ltd.

21. Yong $A G$, Pearce $S$. A beginner's guide to factor analysis: focusing on exploratory factor analysis. Tutorials Quant Methods Psychol. 2013;9(2):7994. https://doi.org/10.20982/tqmp.09.2.p079.

\section{Publisher's Note}

Springer Nature remains neutral with regard to jurisdictional claims in published maps and institutional affiliations. 